\title{
Argentina e Brasil na visão dos think tanks dos Estados Unidos ${ }^{1}$
}

\author{
Argentina and Brazil in the view of the \\ United States' think tanks
}

DOI: $10.21530 /$ ci.v13n1.2018.725

Eduardo Munhoz Svartman²

\section{Resumo}

No decorrer dos anos 2000, Argentina e Brasil chamaram atenção dos think tanks dos Estados Unidos dedicados à América Latina e aos países emergentes, por conta da eleição de governantes progressistas e do maior protagonismo externo desses países, expresso em iniciativas como a liderança da MINUSTAH, a criação de novos mecanismos de concertação regional e na adoção de posições críticas ao sistema liderado pelos EUA, embora não necessariamente identificadas com o bolivarianismo. Esse papel suscitou considerável produção de "experts" a respeito dos dois países no sentido de decifrar essa nova realidade e de orientar a política dos Estados Unidos para a região. O presente estudo analisa como a produção ideacional dos think tanks dos EUA abordou o ciclo de maior protagonismo externo da Argentina e do Brasil, as crises domésticas e os novos governos que chegaram ao poder em 2015 e 2016. São escrutinadas as temáticas dominantes e enfatizados, na análise, os aspectos securitários e estratégicos considerados pelos think tanks como mais relevantes para os Estados Unidos, assim como as recomendações políticas feitas por tais organizações.

Palavras-chave: think tanks; relações Brasil-Estados Unidos; relações Argentina Estados Unidos; países emergentes.

\footnotetext{
Abstract

In the 2000s, Argentina and Brazil caught the attention of the United States think tanks devoted to Latin America and emerging countries. The election of center-left rulers that increased the foreign protagonism of their countries through initiatives such as the leadership

1 Esta pesquisa contou com bolsa CAPES Estágio Sênior, processo número 001583/2015-08.

2 Professor dos Programas de Pós-Graduação em Ciência Política e em Estudos Estratégicos Internacionais da UFRGS. Contato: eduardosvartman@gmail.com

Artigo submetido em 03/11/2017 e aprovado em 19/04/2018.
} 
of MINUSTAH, the creation of new regional organizations and the criticism to the US-led international order, although not necessarily identified with Bolivarianism, really changed the regional landscape. This role has given rise to considerable production of "experts" about the two countries in order to decipher this new reality and to guide US policy towards the region. The present study analyzes how the ideational production of US think tanks addressed the cycle of greater external protagonism in Argentina and Brazil, the domestic crises and the new governments that came to power in 2015 and 2016. The text depicts the predominant issues and is focused on the analysis of the strategic and security aspects considered by the think tanks as most relevant to the United States, as well as the policy recommendations made by these organizations.

Keywords: think tanks; Brazil-United States relations; Argentina-United States relations; rising countries.

\section{Introdução}

As primeiras décadas do século 21 têm sido marcadas por um duplo processo de incremento do protagonismo de países intermediários, usualmente classificados como "emergentes", e de desgaste da credibilidade dos Estados Unidos e de seu compromisso com alguns dos fundamentos da ordem internacional que, desde o fim da Guerra Fria, lideravam quase sem contestação. As mudanças que vêm reconfigurando o ordenamento do sistema internacional se expressam na retomada do protagonismo externo da Rússia, na ascensão econômica (e, em menor escala, militar) da China, na emergência de novos fóruns e articulações internacionais, como o G-20 e o BRICS, e nas iniciativas de vários países intermediários no sentido de ampliar suas margens de autonomia, especialmente nos seus entornos regionais. Como será assinalado adiante, Argentina e Brasil participaram, ainda que em escalas diferentes, dessa dinâmica.

Embora a distribuição do poder militar não tenha sofrido ainda alterações muito significativas desde as longas intervenções no Iraque e Afeganistão, em nome da "guerra global ao terror", e da crise financeira de 2008, as respostas dos Estados Unidos a essa ordem em fluxo têm sido objeto de ampla discussão, na qual se assinala a alternância de opções unilateralistas e protecionistas, que enfraquecem o componente liberal e sua legitimidade, e de opções de concertação e globalistas, que buscam reforçar o compromisso de outros países com a governança do sistema (HURRELL, 2006; KAHLER, 2013). Essa alternância pode ser constatada no predomínio de políticas unilaterais dos governos George W. Bush e Donald Trump 
e de "engajamento" com os chamados "responsible stakeholders" da administração Barak Obama. Também expressa um debate teórico em curso nos EUA entre os advogados da estratégia da contenção dos emergentes (MEARSHEIMER, 2014), da socialização desses na ordem liberal (IKENBERRY, 2011) e da moderação da presença dos Estados Unidos nas regiões e temas considerados vitais para sua hegemonia (POSEN, 2014).

Diferente da Guerra Fria, quando a estratégia da contenção pautou a ação dos Estados Unidos, no presente, cada governo tem feito ajustes conjunturais e por vezes contraditórios que buscam atender tanto às demandas externas quanto ao público interno estadunidense. Nesse ambiente, a definição do que seja o interesse nacional dos EUA na miríade de regiões, temas e agendas específicas é objeto de disputa particularmente forte entre os atores governamentais diretamente envolvidos (Casa Branca, Departamento de Estado, Pentágono, Congresso) e atores sociais que pretendem influenciar tal processo (grupos de pressão, think tanks, lobbies). Diante disso, o objetivo central desse artigo é analisar a produção ideacional de um dos grupos de atores, os think tanks, no que diz respeito ao maior protagonismo internacional da Argentina e do Brasil, às crises domésticas e aos novos governos que chegaram ao poder em 2015 e 2016, de modo a apreender o que, na percepção de um número selecionado de think tanks, tais acontecimentos implicariam para os Estados Unidos. Num período de crise econômica e contestação da liderança norte-americana, de ascensão e queda de governos de esquerda e centro-esquerda na América do Sul, como os dois maiores países da região foram enquadrados por essas organizações, que têm por objetivo influenciar governos e a opinião pública do seu país?

Para dar conta dessa proposta, o presente artigo está organizado da seguinte maneira: esta introdução, uma breve descrição do maior protagonismo observado nas inserções internacionais da Argentina e do Brasil, seguida do papel exercido pelos think tanks no cenário político dos Estados Unidos e do recorte analítico aqui estabelecido. Posteriormente, são apresentadas algumas características institucionais e ideológicas dos think tanks aqui pesquisados para, em seguida, analisar sua produção ideacional a respeito das políticas externa e de defesa da Argentina e do Brasil. Por fim, o artigo encerra com conclusões, onde são apresentadas as conclusões. 


\section{Protagonismo externo da Argentina e do Brasil e o papel dos think tanks}

Na primeira década do século XXI, a ação externa da Argentina deu-se no sentido de alavancar a recuperação da profunda crise econômica e política que abalou o país no início da década de 2000. Para fazer frente à retração da economia e aos impactos sofridos pela sociedade de seu país, que levaram o governo anterior a decretar moratória ao pagamento dos credores externos, o presidente Néstor Kirchner, eleito em 2003, apontou para a recuperação das reservas, reindustrialização e a geração de emprego como suporte para sua estratégia de desendividamento e renegociação da dívida externa do país. Crítico das administrações neoliberais anteriores e dos organismos financeiros internacionais, Kirchner afirmava "pensar o mundo em argentino" e conferiu maior ênfase à presença da Argentina nos foros multilaterais, às relações com a América do Sul e à aproximação com a Venezuela e o Brasil (BUSSO, 2014). Tratava-se, em síntese, de uma inflexão em favor de um modelo autonomista e desenvolvimentista (SIMONOFF, 2009). Tal inflexão esteve amparada num período continuado de forte expansão da economia Argentina, com taxa média de crescimento do PIB superior a $8 \%$ ao ano (BANCO MUNDIAL, 2017).

No campo da defesa nacional, a Argentina manteve o orçamento de defesa severamente reduzido, o que prolongou o quadro de crescente obsolescência de suas Forças Armadas. Entretanto, houve avanços em termos de controle civil sobre os militares (envolvendo tanto a responsabilização de agentes da ditadura pelos crimes cometidos, como mudanças substantivas na educação militar) e do emprego das forças em operações de paz sob o mandato da ONU, o que reforçava seu compromisso com o multilateralismo e estreitou a aproximação com o Brasil, Chile e Uruguai, atores relevantes na MINUSTAH. A adesão argentina à UNASUL e sua atuação em crises como a do acordo de 2009 (no qual a Colômbia esteve a ponto de ceder bases militares aos EUA em seu território), revelam uma disposição para fortalecer os mecanismos regionais multilaterais e manter um padrão autonomista em relação à potência central.

Em 2007, Cristina Fernandez de Kirchner assumiu a presidência da Argentina com um programa continuísta; todavia, ao longo de seus dois mandatos, os cenários interno e externo se mostraram cada vez menos favoráveis. Na esteira do desgaste de 12 anos dos Kirchner à frente da Casa Rosada e da queda do preço internacional dos produtos exportados pela Argentina, em 2015, Maurício Macri venceu as eleições nacionais. Crítico do que define como o populismo de seus 
antecessores, Macri tem adotado um perfil de inserção externa neoliberal e alinhado às potências centrais. Durante sua visita oficial a Washington, em 2017, Macri participou de um evento no Center for Strategic International Studies (CSIS), um dos mais influentes think tanks dos EUA, onde falou em inglês, um ato simbólico relevante a indicar que o governo não mais "pensava em argentino".

No mesmo período, o Brasil viveu um ciclo, em sua ação externa, que partiu de uma crítica aos custos do processo de globalização, ainda nos anos finais do governo Cardoso (SILVA, 2009), para uma maior diversificação e busca por autonomia na administração Lula, seja através da construção de coalizões em organizações internacionais, da criação de novos foros regionais - como a UNASUL, da mobilização de um discurso reformista dos organismos internacionais ou da projeção econômica e política sobre América do Sul, África e Oriente Médio (CERVO, 2010). A isso se soma a implantação de projetos de modernização das suas Forças Armadas a partir da produção doméstica e de iniciativas de integração da indústria de defesa no âmbito da América do Sul, em cooperação com parceiros predominantemente europeus (SVARTMAN, 2014). Mais recentemente, nos governos Dilma Rousseff, tal ciclo se retraiu para níveis mais baixos de protagonismo (SARAIVA, 2016) e, no governo Michel Temer, sofreu uma inflexão, abandonando o discurso reformista, distanciando-se da África e assumindo um discurso voltado à busca de acordos de livre-comércio com a Europa e os Estados Unidos.

Diante da complexidade das transformações em curso e da dificuldade em se estabelecer com maior precisão um padrão de conduta dos Estados Unidos em relação aos países intermediários em geral e a Argentina e Brasil em particular, tanto no que diz respeito aos temas de política externa quanto aos de defesa, evidencia-se a necessidade de uma compreensão mais aprofundada dos processos de formulação dessas políticas. Os think tanks consistem em um espaço social no qual é possível identificar as opções políticas que estão em circulação e disputa no ambiente político de Washington, uma vez que são organizações frequentemente definidas como dedicadas à pesquisa de políticas públicas e ao fornecimento de análises e assessoria que visam prover os dirigentes políticos de elementos para a tomada de “decisões informadas" sobre questões específicas (MCGANN, 2011). Em termos institucionais e legais, os think tanks são organizações da sociedade civil sem fins lucrativos que, nos Estados Unidos, são mantidos majoritariamente por doações do setor privado (fundações, empresas ou pessoas) e, em alguns casos, por doações e contratos governamentais (ABELSON, 2006). 
Embora ainda relativamente pouco investigados na Argentina e no Brasil, os think tanks integram o universo discursivo em que são construídas, testadas, debatidas e difundidas as ideias que embasam o processo de modelagem de distintas políticas públicas em vários países. Em diferentes circunstâncias, os think tanks desempenharam papel ativo na produção das opções de política externa e de defesa nos Estados Unidos, no Reino Unido e, mais recentemente, na União Europeia e em seus membros (STONE; DENHAM, 2004). Tal papel não é linear e nem sempre pode ser imediatamente traduzido em termos de influência direta e mensurável no processo de tomada de decisão estatal. Contudo, é particularmente relevante em ambientes institucionais complexos, no qual vários atores interferem no processo de formulação e execução de políticas, como nos Estados Unidos, onde, junto com a Presidência, os departamentos de Estado e de Defesa, o Congresso e agências como a NSA e a CIA atuam no processo.

Nesses ambientes, os think tanks são aqui pensados como espaços de construção, reprodução e circulação de ideias vocacionadas para modelar o debate público e influenciar a formulação de políticas públicas junto aos agentes governamentais, tendo como princípio de legitimidade a expertise. As noções que informam as formulações estratégicas, a identificação de oportunidades e ameaças, aliados e inimigos e, por fim, o desenho das políticas delas decorrentes não são apenas corolários da estrutura do sistema internacional. Segundo a tradição construtivista, trata-se de percepções socialmente construídas que definem o que se entende por interesse nacional. Conforme Jutta Weldes

os interesses nacionais são construções sociais criadas como objetos significativos a partir dos significados intersubjetivos e culturalmente estabelecidos com os quais o mundo, em particular o sistema internacional e o lugar do Estado nele, é entendido. Mais especificamente, os interesses nacionais emergem das representações - ou, para empregar terminologia mais usual, descrições de situações e definições de problemas - através das quais agentes do Estado e outros atores produzem sentido do mundo ao seu redor. ${ }^{3}$ (WELDES, 1996, p. 280)

3 National interests are social constructions created as meaningful objects out of the intersubjective and culturally established meanings with which the world, particularly the international system and the place of the state in it, is understood. More specifically, national interests emerge out of the representations - or, to use more customary terminology, out of situation descriptions and problem definitions - through which state officials and others make sense of the world around them. 
Nesse sentido, considera-se aqui que os think tanks operam participando do processo de construção ideacional dos chamados interesses nacionais dos Estados Unidos. Ou seja, do que e de quem são seus aliados e parceiros e do que esperar de seus adversários, reais ou potenciais. A produção ideacional dessas organizações está firmemente engajada na construção de identidades e significados a respeito do papel das potências e do que significam, no caso dessa pesquisa, Argentina e Brasil. Deve-se salientar que, apesar da diversidade ideológica, entre os think tanks aqui investigados predominam variantes da visão liberal, nas quais se tende a naturalizar a ordem construída e liderada pelos EUA desde 1945 como sendo um bem coletivo universal ${ }^{4}$. Dessa forma, a questão fundamental que informa essa produção sobre Argentina e Brasil aplica-se aos demais emergentes: em que medida tais países pretendem ser acomodados na ordem liberal e em que medida eles são forças que desafiam a ordem e pretendam modificá-la ou criar outra.

Deve-se, ainda, destacar que os think tanks são relevantes não apenas por sua disposição para influir no processo decisório, mas também por contribuir para modelar o debate e a opinião pública em torno de agendas e ideias específicas. No que diz respeito a países que contam com poucos especialistas entre os atores em Washington, como Argentina e Brasil, a produção ideacional difundida pelos think tanks é consumida por quadros da diplomacia estadunidense, das empresas de consultoria, das agências de classificação de risco, da imprensa e de associações de negócios. As ideias construídas e propagadas pelos think tanks nesses ambientes, através de diferentes meios, como relatórios, artigos em jornais, conferências, mesas redondas e reuniões reservadas, contribuem para a formação de um consenso (o chamado "common ground") que informa o desenho de políticas governamentais, recomendações ao setor privado e decisões de investimento.

\section{Panorama dos think tanks investigados e recorte analítico}

Os Estados Unidos é o país que abriga o maior número de think tanks no mundo, alguns especializados em determinadas agendas e outros que, através de programas específicos, abarcam ampla variedade de temas. Alguns se colocam como "bipartidários" e evitam uma identidade programática mais evidente, ao passo que outros colocam-se claramente na posição de promover, no mercado

4 Para os contornos dessa visão liberal, ver Zahran, 2012. 
de ideias, determinada agenda (ABELSON, 2006). Diante dessa diversidade, para esta pesquisa, foi feito um primeiro levantamento dos think tanks que, entre 2000 e 2016, mantiveram programas institucionalizados ou especialistas (experts) que publicaram de forma continuada análises sobre a atuação internacional da Argentina e do Brasil. Tal recorte permitiu descrever o panorama que se segue.

De forma geral, a América Latina é uma região de baixa prioridade para os governos estadunidenses, o que torna o tema igualmente restrito no espaço dos think tanks desse país. Em termos de visibilidade, Argentina e Brasil acabam eclipsados por México, Cuba e Colômbia, países mais próximos e que mobilizam agendas políticas e securitárias profundamente entranhadas no cenário político dos Estados Unidos. Em Washington, identificou-se apenas três organizações dedicadas integralmente à região. O Washington Office on Latin America (WOLA) foi fundado em 1974 por organizações religiosas preocupadas com as violações promovidas pelas ditaduras militares latino-americanas apoiadas pelo governo dos EUA. Desde então, o WOLA tem uma agenda fortemente dedicada aos direitos humanos. Atualmente, sua produção está voltada para temas como violência policial, narcotráfico e migrações (para os EUA) e pouco tem publicado a respeito da Argentina e do Brasil. Também fundado nos anos de 1970, o Council on Hemispheric Affairs é um dos poucos think tanks dos EUA que pode ser classificado como de esquerda. De estrutura e orçamento bastante modestos, o COHA conta com um número considerável de voluntários em seu staff, que alimentam uma produção continuada sobre os países da região e as relações com os Estados Unidos. Contudo, seu impacto nos meios decisores de Washington, pouco receptivos a visões de esquerda, é modesto.

Dentre os três, o mais influente é o Interamerican Dialogue, mais conhecido como The Dialogue. Fundado em 1982, declara o objetivo de promover governança democrática, equidade social e prosperidade através das Américas. $\mathrm{O}$ embaixador Sol Linowitz (ex-dirigente da Xerox e negociador do governo Carter para os acordos envolvendo a soberania do canal do Panamá) foi um dos fundadores dessa organização que, além de publicar artigos e op-eds assinados por seus quadros, opera como uma "membership organization". Entre seus aproximadamente 100 membros, encontram-se os ex-presidentes Ernesto Zedillo, Fernando Henrique Cardoso e Michelle Bachelet, os presidentes Juan Manuel Santos, legisladores de vários países da região e dirigentes do setor privado dos EUA e da América Latina. Possui, ainda, um programa de membros corporativos, do qual fazem parte empresas do setor industrial como BMW e Mitsubishi e do setor financeiro 
como Liberty Mutual. Entre seus maiores doadores de recursos, estão a Fundação Ford, Fundação Avina, Chevron e organizações financeiras multilaterais, como o Banco Interamericano de Desenvolvimento e a Corporação Andina de Fomento (THE DIALOGUE, 2015).

Há também think tanks maiores com programas dedicados à América Latina ou a países específicos. O Woodrow Wilson International Center for Scholars, um dos maiores think tanks dos Estados Unidos, abriga 15 centros regionais, três deles dedicados aos países da região: o Mexico Institute, o Brazil Institute e o Latin America Program, que cobre todos os demais países do subcontinente. Criado em 2006, o Brazil Institute é desdobramento de um programa implantado no ano 2000 pelo embaixador do Brasil, que pretendia promover a "presença" do Brasil em Washington. Atualmente, o programa não recebe apoio do governo brasileiro, os doadores que aportam mais recursos são a Interfarma, uma associação de empresas do setor farmacêutico estabelecidas no Brasil, e empresas como Coca-Cola, Gerdau, Chevron, Coteminas e Ayres (WILSON CENTER, 2016). O Latin America Program, embora abarque um grande número de países, tem mantido uma produção continuada a respeito da Argentina. O foco do programa está em governança democrática, inclusão e segurança cidadã, além, é claro, das relações entre os Estados Unidos e a América Latina.

A Brookings Institution é considerada um dos mais influentes, senão o mais influente, think tank do mundo (MGGANN, 2015). Fundada em 1916, possui orçamento multimilionário e um quadro de centenas de pesquisadores em tempo integral e parcial. Possui cinco programas principais (Estudos Econômicos, Política Externa, Economia Global e Desenvolvimento, Estudos de Governança e Política Metropolitana) e vários projetos dedicados a regiões ou temas específicos. Argentina e Brasil são contemplados por dois programas, um bastante modesto, dedicado à América Latina, e outro, mais amplo e com mais recursos, dedicado a, em suas palavras, "analisar as principais dinâmicas em curso no século XXI e apresentar ideias e estratégias que orientem países e lideranças no sentido de preservar e renovar a ordem internacional estabelecida". Trata-se do projeto "Order from Chaos" (BROOKINGS, 2015). Embora divulgue suas ideias através de mídias digitais, artigos em jornais de grande circulação e programas em canais de notícias, a Brookings também publica trabalhos de maior fôlego de seus "experts" em livros impressos, que seguem regras semelhantes às do meio universitário, o que a aproxima mais do campo acadêmico (MEDVETZ, 2012). 
Outro think tank relevante que dedicou atenção aos dois países em questão foi o Council on Foreign Relations (CFR), também uma organização fundada no início do século XX. Sua disposição para influência política pode ser avaliada desde cedo: no entreguerras, o CFR desempenhou um papel importante, junto com seu congênere britânico, a Chatham House, no sentido de difundir ideias ligadas ao maior protagonismo externo dos Estados Unidos e em favor da aliança com o Reino Unido (LEGRO, 2000; PARMAR, 2004) e, mais tarde, na produção do consenso em favor dos acordos de Bretton Woods (SMITH, 1991). Desde 1922, o Council on Foreign Relations publica a conhecida revista Foreign Affairs e abriga um grande número de programas dedicados a diferentes temas e regiões, um deles dedicado à América Latina.

Os think tanks que se posicionam no campo conservador do espectro político dos Estados Unidos, como a Heritage Foundation e o American Enterprise Institute, não possuem programas dedicados aos países aqui abordados ou mesmo à região como um todo. No entanto, seus quadros há décadas dedicam atenção à Cuba e, desde o início do século XXI, ao que definem como a volta do populismo na América Latina. Por conta disso, ambos os think tanks têm publicado textos sobre assuntos domésticos e externos da Argentina e do Brasil desde a eleição de Néstor Kirchner e Lula da Silva.

Os think tanks referidos nesta seção são uma fração diminuta dos aproximadamente 1800 existentes nos Estados Unidos, contudo são aqueles que maior atenção dedicaram à Argentina e ao Brasil e cuja atuação, no chamado "mercado de ideias", tem tido maior impacto na modelagem do debate público e na percepção de atores governamentais e privados a respeito dos dois países. Uma vez definidos e contextualizados os think tanks investigados, empreendeu-se o levantamento dos livros, relatórios e artigos publicados por especialistas a eles vinculados entre os anos 2000 e $2016^{5}$. Nas próximas seções, escrutinam-se os aspectos estratégicos e securitários relacionados à Argentina e ao Brasil considerados mais relevantes pelos think tanks mapeados e as recomendações políticas por eles feitas.

5 Os think tanks promovem eventos (mesas redondas, debates, conferências) e incentivam seus especialistas a comentar notícias e a participar de programas de televisão. Grande parte desse material está disponível em forma de vídeos transmitidos online ou nos sites dos próprios think tanks. É importante salientar que nesta pesquisa empregou-se apenas material impresso, uma vez que o material audiovisual demandaria outras ferramentas metodológicas. 


\section{Visões sobre a Argentina}

Quando Néstor Kirchner assumiu seu cargo na Casa Rosada, a visão dos think tanks que se manifestaram sobre o assunto foi de uma espécie de expectativa positiva. Embora assinalassem o emprego da retórica nacionalista e antiamericana durante a campanha, não associaram o novo presidente argentino ao populismo ou a uma eventual coalizão de governos de esquerda na região - Hugo Chaves estava no poder na Venezuela desde 1999 e Lula da Silva no Brasil desde janeiro de 2003 (HAKIM, 2003; FALCOFF, 2004). Provavelmente devido à percepção da intensidade da crise argentina, a expectativa era de que Kirchner conseguisse consolidar-se no poder e encaminhar uma solução para o problema da dívida, para o qual se recomendava apoio do governo dos EUA, especialmente junto ao Fundo Monetário Internacional.

Em 2005, o presidente do Inter-American Dialogue, Michael Shifter, publicou em coautoria um artigo que evitava descrever os novos governos sul-americanos como de esquerda ou populistas, argumentando que disciplina fiscal e ortodoxia econômica eram observadas na Argentina e no Brasil, assim como no Uruguai de Tabaré Vasquez e no Chile de Ricardo Lagos, salientando, ainda, que as prescrições do FMI para a região produziram resultados decepcionantes. Para os autores,

O rótulo "esquerdista” é agora uma construção artificial que deve ser descartada. Isso confunde mais do que esclarece. Nas mentes de muitos, o termo ainda está associado a políticas econômicas irresponsáveis e a recursos populistas, uma receita de instabilidade política. No entanto, uma avaliação do Chile, do Brasil e até mesmo da Argentina sugere que tais preocupações podem ser anacrônicas. Longe de seguir esse caminho, esses países buscam o equilíbrio certo entre crescimento econômico e atenção séria à agenda social urgente ${ }^{6}$ (SHIFTER; JAWAHAR, 2005).

A partir de 2006, contudo, o discurso a respeito da Argentina começou a mudar. O estreitamento dos laços com a Venezuela foi percebido como nocivo, uma vez que reforçaria a construção de uma "aliança antiestadunidense na América do Sul e no Caribe" (SCHIFTER, 2006) e que o governo argentino estaria

6 The "leftist" label is by now an artificial construct that should be jettisoned. It confuses more than it clarifies. In the minds of many, the term is still associated with irresponsible economic policies and populist appeals, a recipe for political instability. Yet a review of Chile, Brazil and even Argentina suggests that such concerns may be anachronistic. Far from pursuing such a path, these countries are seeking the right balance between economic growth and serious attention to the urgent social agenda. 
utilizando recursos oriundos da Venezuela para reforçar sua base doméstica e sua capacidade de negociação com o FMI e os credores do Clube de Paris (ROBERTS, 2007). A eleição de Cristina Fernandez de Kirchner não foi recebida com a mesma benevolência que a de seu predecessor. O Dialogue passou a associar os Kirchners ao populismo e a explicar o crescimento econômico registrado na Argentina ao boom das commodities e ao não pagamento da dívida externa (HAKIM, 2007; LOSER, 2017). Como seria de se esperar, think tanks conservadores como a Heritage e o American Enterprise Institute subiram o tom e não apenas passaram a enfatizar vínculos do governo argentino com o venezuelano, mas passaram a promover eventos, publicar relatórios e artigos severamente críticos e em tom de denúncia, à semelhança do que já faziam com Venezuela e Cuba. As negociações em torno da dívida argentina, a reestatização de empresas privatizadas no passado, os conflitos com o grupo Clarín e com o setor agrário-exportador eram usados para descrever o governo como sem credibilidade, sem respeito ao Estado de direito e aliado do "populismo estatista" da Venezuela. Por conta disso, especialistas conservadores recomendavam:

O Governo e o Congresso devem levar a cabo uma ampla revisão da política dos EUA em relação ao regime de Kirchner e assumir seriamente a ameaça representada tanto aos Estados Unidos quanto à América Latina pelas políticas populistas e estatistas de Kirchner. A Argentina não deve receber favores políticos do governo dos EUA? . (ROBERTS, 2011)

Expoentes do conservadorismo republicano na região, como o ex-embaixador dos EUA na OEA, Roger Noriega, alimentaram uma longa campanha contra o governo argentino, classificando-o como "populista”, "autoritário”, “desastroso" e cunhando expressões como a "dinastia Kirchner" (NORIEGA, 2013; 2015). Apesar da retórica dos conservadores, a Argentina não foi percebida pelos think tanks dos EUA como um ator securitário importante (ou seja, como ameaça existencial), o que pode ser explicado pelos baixos orçamentos de defesa e pela distância em relação às regiões prioritárias para os Estados Unidos. No entanto, houve um processo de securitização da ação externa argentina pelos atores aqui investigados no que diz respeito às relações com o Irã. O aumento do comércio entre Argentina e Irã não foi percebido como decorrência da diversificação geral

7 The Administration and Congress must undertake comprehensive review of U.S. policy toward the Kirchner regime and take the threat posed on both the U.S. and Latin America by the Kirchner's populist and statist policies seriously. Argentina should receive no political favors from the U.S. government. 
do comércio platino, mas de uma eventual aliança que se estaria estabelecendo entre os dois países; apesar da desproporção, o tema era enquadrado de forma semelhante às aquisições de armamentos russos pela Venezuela. Em várias ocasiões, textos publicados por especialistas do American Enterprise Institute procuraram estabelecer uma conexão clandestina entre Buenos Aires, Caracas e Teerã. A reabertura, em 2013, das investigações do atentado que, em 1994, matou 86 pessoas em Buenos Aires e a morte do promotor encarregado, um dia antes de se pronunciar perante o Congresso em 2015, foram igualmente utilizados para apresentar a Argentina vinculada a "governos párias" (NORIEGA, 2015; 2016).

A eleição de Maurício Macri, em 2015, foi recebida com grande entusiasmo pelos think tanks dos EUA. Antes mesmo de sua posse, dada sua conhecida atuação como oposicionista dos Kirchners e sua orientação neoliberal, alguns especialistas passaram a descrever a Argentina como o novo "grande aliado dos Estados Unidos" e o protagonista de mudanças na balança de poder da região (NORIEGA, 2015). Argumentava-se que, ao reorientar sua política externa, o novo governo argentino viabilizaria uma "oportunidade única” para fomentar políticas de livre-mercado na América Latina. Think tanks conservadores, como o American Enterprise Institute, passaram a falar em "liderança construtiva" de Buenos Aires, o que seria importante para reverter os interesses de Moscou e Teerã na América Latina e para fornecer aos EUA um parceiro regional para lidar com a Venezuela. A visita oficial de Barak Obama, em março de 2016, foi igualmente festejada como o "recomeço" das relações entre Argentina e Estados Unidos e as posições do governo argentino contra o governo venezuelano e em favor da oposição desse país foram saudadas como compromisso com a democracia e os direitos humanos (WAYNE; GUTIERREZ, 2016).

A eleição de Donald Trump, em novembro de 2016, e a implantação de sua agenda protecionista, atingindo inclusive exportações argentinas, abalaram a convicção de uma ampla convergência entre os dois países. Embora a visão dos think tanks seja claramente favorável à agenda de Macri, especialistas, como Cynthia Arnson, do Wilson Center, argumentam que

A antipatia do "America First" de Trump a comércio livre, mercados abertos e globalização é a antítese direta dos esforços da Macri para atrair o investimento estrangeiro e aprofundar a integração da Argentina na região e no mundo ${ }^{8}$. (ARNSON, 2017)

8 Trump's "America First" antipathy to free trade, open markets, and globalization is the direct antithesis of Macri's efforts to attract foreign investment and deepen Argentina's integration in the region and with the world. 
Nesse sentido, quando da visita de Macri a Washington, os think tanks recomendaram que ambos os governos evitassem as diferenças comerciais e buscassem consolidar os pontos em comum em questões como cooperação no combate ao narcotráfico, cooperação científica e na "questão" da Venezuela.

Além do que é objeto de interesse dos think tanks, convém assinalar também o que é silenciado. Ao contrário do que se verificou em relação ao Brasil, temas como a criação da UNASUL e, especialmente, o Conselho de Defesa Sul-Americano, não aparecem associados à Argentina. Tampouco repercutiu nesse meio a contribuição argentina à MINUSTAH. As políticas externa e de defesa foram temas periféricos na produção ideacional dos think tanks a respeito da Argentina, a menos que envolvessem países como Venezuela ou Irã. Por outro lado, predominaram os assuntos de âmbito doméstico que envolviam interesses internacionais, como o endividamento e a reestatização de empresas com controle acionista estrangeiro.

\section{Visões sobre o Brasil}

Ao longo do período estudado, a produção ideacional dos think tanks dos EUA a respeito do Brasil percorreu um ciclo partindo do entusiasmo, que enfatizou os traços comuns e convergências entre os dois países, passando pela identificação de dissensos a respeito do funcionamento do sistema internacional, o que gerou uma série de dúvidas quanto às posições assumidas e às capacidades efetivas do Brasil e, por fim, com a retração e agravamento das crises econômicas e política, desaguou na decepção quanto ao país e suas instituições domésticas.

As abordagens do maior ativismo externo do Brasil na primeira década do século XXI estiveram associadas a uma descrição, inicialmente otimista, de uma série de "ativos" (assets) conquistados pelo país nos últimos anos. Tais ativos seriam o controle da inflação, o que revertia uma visão arraigada desde os anos de 1980 de um país economicamente instável; a consolidação da democracia, com a eleição de governos "à esquerda do centro" que, não obstante, mantinham as regras do jogo político e o cumprimento dos contratos econômicos; um período relativamente longo de crescimento econômico em ambiente de economia de mercado e a adoção de programas de redução da pobreza bem-sucedidos.

O exemplo mais importante dessa narrativa positiva que enfatiza aspectos em comum e sugere maior aproximação e coordenação entre os Estados Unidos 
e o Brasil é o extenso relatório publicado pelo Council on Foreign Relations, em 2011, intitulado Global Brazil and U.S.-Brazil Relations (BODMAN, WOLFENSOHN, SWEIG, 2011). O documento de 110 páginas, resultado do trabalho de uma forçatarefa, afirma que os Estados Unidos e o Brasil são ambas “jovens democracias multiétnicas que defendem valores comuns em relação ao livre mercado, Estado de direito, direitos individuais, liberdade religiosa e diversidade e igualdade"9 (2011, p. 4). O relatório enfatiza não apenas o papel do Brasil no plano regional, mas sua relevância global em questões ligadas à economia, meio ambiente, energia e diplomacia, sendo apresentado como um dos poucos países destinados a modelar o século XXI (p. x). Por conta disso, em várias passagens, o documento recomenda que os Estados Unidos adaptem sua política a esse "novo" ator mais “assertivo e independente", de modo a incrementar as relações bilaterais e, em especial, a assegurar seus próprios interesses numa ordem internacional mais multipolar e menos previsível através da interação direta entre as lideranças e corpos diplomáticos, o que, ainda segundo o documento, configuraria uma "relação madura” entre os dois países. Em função disso, o relatório recomendou que, entre outras iniciativas, o governo Obama apoiasse o pleito brasileiro por um assento permanente no Conselho de Segurança das Nações Unidas (p. x, 47s).

Perpassa, nessa narrativa de valores compartilhados, um esforço para enfatizar os pontos de convergência entre os dois países e definir um papel "construtivo” do Brasil para a legitimação, gestão e preservação da ordem internacional liderada pelos Estados Unidos. Num cenário regional de atritos com os países da ALBA, liderados pela Venezuela, e de instabilidade econômica, o Brasil foi descrito como um ator comprometido com democracia, estabilidade e economia de mercado. No plano global, com a ascensão da China e a retomada da Rússia (normalmente descritas como potências autoritárias e desafiadoras da ordem internacional e da liderança dos EUA), o Brasil foi descrito, apesar do incômodo com o BRICS, como ator comprometido com democracia, direitos humanos e com a manutenção, moderadamente reformada, da ordem internacional.

É nesse sentido que se deve compreender a recepção majoritariamente positiva dos programas de modernização das Forças Armadas brasileiras. Havia a expectativa de que, contando com maiores capacidades, as Forças Armadas

9 Multiethnic, young democracies that uphold common values with respect to free markets, rule of law, individual rights, religious freedom, and diversity and equality. 
brasileiras poderiam cooperar com os Estados Unidos em questões de segurança marítima e missões de paz ou, ainda, contribuir para a estabilidade em regiões em que a presença dos EUA teria maior custo político. Havia ainda o interesse econômico da indústria de defesa, importante financiadora de vários think tanks, em ser fornecedora dos programas militares do Brasil.

Ao longo do período estudado, o Brasil e os Estados Unidos se posicionaram de forma oposta em uma série de questões na arena internacional. Algumas divergências são históricas, como a adesão brasileira aos princípios de autonomia, soberania e não intervenção, e foram atualizadas em uma série de crises como as do Iraque, da Líbia e da Síria. Certamente o ponto mais delicado, contudo, foi a intermediação, junto com a Turquia, do acordo sobre o enriquecimento de combustível nuclear iraniano em 2010. Desde então, se difundiu a percepção de que as iniciativas brasileiras junto ao BRICS, ao "Sul Global” e nos organismos multilaterais visam restringir a ação dos EUA:

O Brasil busca revisões e reformas que sejam efetivamente capazes de limitar o comportamento unilateral dos EUA (...) [O Brasil] procurou rever as normas vigentes para favorecer mais explicitamente países em desenvolvimento, tais como o reforço do princípio da igualdade de soberania ou demandando que as grandes potências sigam as regras. Estes aspectos revisionistas da política externa do Brasil têm colocado desafios às preferências das potências estabelecidas $^{10}$. (MARES; TRINKUNAS, 2016).

A crise na Ucrânia e a incorporação da Criméia pela Rússia em 2014 trouxeram à tona de novo os esquemas de análise da Guerra Fria em Washington. A posição brasileira, contrária a uma sanção na ONU como foi articulada pelos EUA, foi criticada pelos think tanks dos EUA e começou a alimentar dúvidas quanto ao compromisso, moderadamente reformista, do Brasil com a ordem internacional liberal. Especialistas como Ted Piccone, da Brookings, continuavam a enfatizar o compromisso do Brasil com a democracia e os direitos humanos e a sustentar que o Brasil detém "potencial” para se tornar uma liderança global, porém sua vinculação às "potências autoritárias” do BRICS (Rússia e China) levanta dúvidas

10 Brazil seeks revisions and reforms that would make [it] effective in fully constraining US unilateral behavior (...) [Brazil] has tried to revise current norms to favor developing states more explicitly, such as reinforcing the norm of sovereign equality or making demands that great power follow the rules. These revisionist aspects of Brazil's foreign policy therefore have posed challenges to incumbent great power preferences. 
a respeito de como o Brasil se comportaria uma vez alcançadas posições de maior poder (PICCONE, 2016). Essas dúvidas se acentuaram quando a crise econômica e a instabilidade política interna começaram a minar a capacidade de ação externa do Brasil. Especialistas em diferentes think tanks começaram a publicar textos questionando a capacidade brasileira de manter as iniciativas do país na América do Sul, na África, junto aos fóruns multilaterais e de ser capaz de “entregar” bens comuns que pudessem sustentar uma posição de liderança.

A progressiva crise doméstica que se seguiu às eleições de 2014, cujo desfecho ainda não se pode vislumbrar, alimentou a decepção dos think tanks dos EUA quanto a um Brasil global, estável e promotor do desenvolvimento e do reformismo moderado da ordem internacional. Um Brasil "responsible stakeholder" com o qual os EUA poderiam estabelecer uma relação “construtiva” nos setores de interesse mútuo (apesar das discordâncias em vários temas) já não fazia parte da produção ideacional dos think tanks. Desde o impeachment de Dilma Rousseff, os think tanks que se ocuparam do Brasil priorizaram temas domésticos como corrupção, crise política, recessão e tentaram decifrar o novo governo de Michel Temer. Embora houvesse expectativas de reformas liberalizantes e de um incremento das relações comerciais com os Estados Unidos e a Argentina (O’NIELL, 2016), a apreciação dominante tem sido bem menos otimista. Para Peter Hakim (2016), do The Dialogue, a economia deprimida e o caos no Congresso causado pelos escândalos de corrupção são motivos suficientes para que os EUA tenham cautela em se relacionar com o Brasil. Em 2016, havia ainda o questionamento em relação à legitimidade do processo de impeachment, considerando o teor das acusações e a credibilidade dos parlamentares que julgaram a presidente, vários deles acusados de corrupção.

Especialistas de think tanks conservadores, como o American Enterprise Institute, apesar de concordar com medidas de restrição orçamentária e reformas do setor trabalhista e de pensões propostas pelo governo Temer, têm se mostrado bastante céticos quanto à capacidade desse governo e do Congresso, de fato, levarem adiante essa agenda que, no seu entender, recuperaria o país da presente crise. Embora o Brasil ainda seja descrito como uma das maiores economias mundiais, a possibilidade de o país ter que recorrer novamente a empréstimos do FMI vem sendo ponderada. Por conta disso, o AEI recomenda que o governo dos Estados Unidos não reduza sua participação e seu papel nessa organização, uma vez que ela poderá ter que atuar no seu próprio “quintal” (LACHMAN, 2017). 


\section{Conclusões}

A atuação internacional da Argentina e do Brasil despertaram maior atenção dos think tanks dos Estados Unidos no início do século XXI do que em períodos anteriores, quando raramente esses países eram abordados individualmente e permaneciam diluídos no termo "Latin America". A redistribuição do poder mundial, o fenômeno dos emergentes, a eleição de governos de esquerda e o caráter mais proativo das políticas externas da Argentina e do Brasil, tanto em espaços tradicionais como em novos, tais como o G-20 e a UNASUL, fizeram com que os think tanks dos Estados Unidos empreendessem um esforço de produção ideacional a respeito desses "novos" atores.

A eleição de Néstor Kirchner foi recebida pelos think tanks com uma atitude de "esperar e ver" (wait and see), na qual se relevava o que era identificado como a retórica nacionalista e antiamericana do presidente - porém, contava a seu favor a expectativa de superação da crise pela qual a Argentina passava. Os termos utilizados para descrever as políticas externa e doméstica dos dois mandatos de Cristina Kirchner foram bem menos benevolentes. Ainda que os fatores domésticos tenham dominado a agenda temática, as relações da Argentina com a Venezuela e com o Irã alimentaram uma produção ideacional fortemente negativa e ideologizada a respeito do país. A eleição de Mauricio Macri, por sua vez, foi celebrada com a mesma intensidade, assim como sua posição de crítica aberta ao governo venezuelano e de alinhamento com os Estados Unidos.

Com relação ao Brasil, os think tanks investigados alimentaram inicialmente uma expectativa bastante positiva, na qual se esperava que o Brasil contribuísse com a "divisão do fardo" da manutenção política e securitária da ordem internacional. O Brasil era descrito como uma liderança responsável, que exportava um modelo de desenvolvimento democrático, inclusivo e de livre-mercado. Por conta disso, alguns think tanks desenhavam o Brasil em oposição à Venezuela. Os ambiciosos programas de modernização das Forças Armadas brasileiras não foram securitizados e, sim, descritos como oportunidade para a indústria de defesa estadunidense e para a consolidação do Brasil como ator internacional estabilizador capaz de atuar em regiões que os Estados Unidos não estariam dispostos. Essas expectativas, em grande medida, não se verificaram. $\mathrm{O}$ acumulo de divergências entre os dois países e a retração internacional do Brasil alimentaram uma produção que salientou dúvidas e decepção quanto ao "Consenso de Brasília". A crise doméstica 
e o governo Michel Temer acentuaram essa visão. O processo de impeachment foi classificado como “legal porém maculado” pelo Dialogue e, para especialistas da Brookings, a trajetória brasileira de ascensão foi interrompida por conta da fragilidade das instituições domésticas brasileiras (MARES; TRINKUNAS, 2016).

O novo governo de Donald Trump, claramente protecionista e crítico dos acordos de livre-comércio anteriormente negociados, tem sido descrito como um desafio às atuais políticas externas da Argentina e do Brasil. Nesse novo cenário, em que os Estados Unidos voltam-se para uma estratégia de moderação de sua presença nas regiões e em temas percebidos como menos relevantes ou urgentes - e a América do Sul é uma delas -, o alinhamento argentino e brasileiro, até o momento, não reverteu a perda de relevância dos dois países diante de Washington. Por fim, e a título de motivação para novas pesquisas, é importante notar que, para os think tanks aqui investigados, o novo governo dos Estados Unidos também representa um desafio, uma vez que põe em questão alguns consensos partilhados por essas organizações em torno da chamada ordem liberal internacional.

\section{Referências}

ABELSON, Donald. A capitol idea: think tanks and US foreign policy. Toronto: McGillQueen's University Press, 2006.

ARNSON, Cynthia. U.S.-Argentine Relations and the Visit of President Mauricio Macri. Wilson Center. Washington, DC:, 2017.

BANCO MUNDIAL. < www.data.worldbank.org > , último Acesso em: 30/11/2017.

BODMAN, Samuel, WOLFENSOHN, James e SWEIG, Julia (orgs.). Global Brazil and

U.S.-Brazil Relations. Independent Task Force Report No. 66. Washington, DC: Council on Foreign Affairs, 2011.

BROOKINGS. Annual Report 2015. Washington, DC. 2015.

BUSSO, Anabella. Los vaivenes de la política exterior argentina re-democratizada

(1983-2013). Reflexiones sobre el impacto de los condicionantes internos. Estudios Internacionales. Chile, v. 177, 2014.

CERVO, Amado. Brazil's Rise on the International Scene: Brazil and the World. Revista

Brasileira de Política Internacional. 53 (special edition): 7-32, 2010.

FALCOFF, Mark. Argentina and the United States: some reflections on recent developments. 2004. Disponível em: < www.aei.org/publication/argentina-and-the-united-states/ > . Último Acesso em: 22/06/2017. 
HAKIM, Peter. Kirchner deserves US good will. Financial Times. July 23, 2003. Disponível em: < http//archive.thedialogue.org/page.cfm?pageID $=32 \&$ pubID $=1454 \& s=$ Kirch ner\&mode = print $>$. Último Acesso em: 20/06/2017.

HAKIM, Peter. New president's challenge’s. Miami Herald. December 7, 2007. Disponível em: <http//archive.thedialogue.org/page.cfm?pageID $=32 \&$ pubID $=1147 \&$ s $=$ Kirchn er\&mode $=$ print $>$. Último Acesso em: 20/06/2017.

HAKIM, Peter. Defrosting US-Brazilian Relations. The Dialogue. Washington, DC, 2016. HURRELL, Andrew. Hegemony, liberalism and global order: what space for would-be great powers? International Affairs 82, 1 (2006) 1-19.

IKENBERRY, John. Liberal Leviathan. The origins, crisis, and transformation of the American World Order. New Jersey: Princeton University Press, 2011.

KAHLER, Miles. Rising powers and global governance: negotiating change in a resilient status quo. International Affairs. 89:3 (2013) 711-729.

LACHMAN, Desmond. Brazil's woes are 'Exhibit A' for why Trump shouldn't batter IMF. Washington, DC: AEI, 2017.

LEGRO, Jeffrey. Whence American Internationalism. International Organization, Vol. 54, No. 2 (Spring, 2000), pp. 253-289.

LOSER, Claudio. What's at Stake as Macri Meets Today With Trump? Latin American Advisor. Washington, DC, 2017.

MARES David, TRINKUNAS, Harold. Aspirational power: Brazil on the long road to global influence. Washington, DC: Brookings Institution Press, 2016.

McGANN, James. Global Think Tanks: Policy Networks and Governance. New York: Routledge, 2011.

McGANN, James. 2014 Global Go To Think Tank Index Report. Philadelphia: University of Pennsylvania, 2015.

MEARSHEIMER, John. The tragedy of great power politics. Updated Edition New York: Norton, 2014.

MEDVETZ, Thomas. Think Tanks in America. Chicago: The University of Chicago Press, 2012.

NORIEGA, Roger. Argentina's Race to the Bottom. Washington, DC: AEI, 2013.

NORIEGA, Roger. Argentina's Road to Recovery. Washington, DC: AEI, 2015.

NORIEGA, Roger. Fresh evidence emerging of Iran's deadly nuclear and terror ties to Argentina. Washington, DC: AEI, 2016.

O'NIELL, Shannon. A Game of Inches: The Uncertain Fight Against Corruption in Latin America. Washington, DC: CFR, 2016.

PARMAR, Inderjeet. Think tanks and power in foreign policy: a comparative study of the role and influence of the Council on Foreign Relations and the Royal Institute of International Affairs, 1939-1945. New York: Palgrave, 2004. 
PICCONE, Ted. Five rising democracies and the fate of the international liberal order. Washington, DC: Brookings Institution Press, 2016.

POSEN, Barry. Restraint: a new foundation for US Grand strategy. Ithaca: Cornell University Press, 2014.

ROBERTS, James. Argentina: implications for the U.S. if the First Lady Cristina Fernandez de Kirchner becomes President. Washington, DC: AEI, 2007.

ROBERTS, James. Holding the Kirchners accountable for the Argentina's free fall. Washington, DC: AEI, 2011.

SARAIVA, Miriam. Os limites da política externa de Dilma Rousseff para América do Sul. Revista Relaciones Internacionales, v. 25, p. 81-97, 2016.

SCHIFTER, Michael. Más que un giro a la izquierda. La Opinión (Los Angeles). January, 1 2006. Disponível em: < http://archive.thedialogue.org/page.cfm?pageID = 32pubI $\mathrm{D}=1118 \&=$ Kirchner\&mode $=$ print. Último Acesso em: 20/06/2017.

SHIFTER, M. \& JAWAHAR, V. Latin America Defies Old Labels. Los Angeles Times. March, 01, 2005.

SILVA, André Reis da. Do otimismo liberal à globalização assimétrica: a política externa do governo Fernando Henrique Cardoso (1995-2002). Curitiba: Juruá, 2009.

SIMONOFF, Alejandro. Regularidades de la Política Exterior de Néstor Kirchner CONfines, 5/10 agosto-diciembre 2009.

SMITH, James. The Idea Brokers: Think Tanks and the Rise of the New Policy Elite. New York: Free Press, 1991.

STONE, Diane and DENHAM, Andrew (eds.). Think tank traditions: policy research and the politics of ideas. Manchester: Manchester University Press, 2004.

SVARTMAN, Eduardo. A Agenda de Defesa do Brasil para a América do Sul. In: Carlos Schmidt Arturi. (Org.). Políticas de Defesa, Inteligência e Segurança. Porto Alegre: UFRGS/CEGOV, 2014.

THE DIALOGUE. 2013-2014 Annual Report. Washington, DC: 2015.

WAYNE, Earl; GUTIERRES, Lino. A New Beginning with Argentina. Buenos Aires Herald, 22 de março de 2016.

WILSON CENTER. Brazil Institute Annual Report. Washington, DC: 2016.

WELDES, Jutta, Constricting national interests. European Journal of International Relations 1996; 2; 275-318.

ZAHRAN, Geraldo. Tradição liberal e política externa nos Estados Unidos: um diálogo com interpretações realistas e idealistas. Rio de Janeiro: Apicuri, 2012. 